\title{
A Política Nacional de Promoção da Saúde: texto e contexto de uma política
}

\author{
A National Health Promotion Policy: text and context of a policy
}

Patrícia Ferrás Araújo da Silva', Tatiana Wargas de Faria Baptista²

RESUMO O artigo discute os argumentos presentes nos diferentes textos da Política Nacional de Promoção da Saúde no Brasil, analisando os documentos de 2002, 2006 e 2014 e reunindo elementos para compreender como a promoção da saúde ganhou institucionalidade e entrou na agenda governamental. Conclui-se que os três documentos da Política representam momentos distintos, revelando tensões em sua definição, o que pode tanto reforçar uma tendência prescritiva da saúde como produzir o debate acerca dos determinantes sociais em uma concepção ampliada de saúde. Politizar tal debate é o primeiro passo, para não se correr o risco de se afirmar uma política que, principalmente, culpabiliza e responsabiliza o indivíduo.

PALAVRAS-CHAVE Promoção da saúde; Política de saúde; Formulação de políticas.

ABSTRACT The article discusses the arguments present in the various texts concerning the National Policy of Health Promotion in Brazil and analyzes the documents released in the years 2002, 2006 and 2014, bringing together elements so to understand how health promotion achieved a legal knowledge, becoming part of the government agenda. It concluded that the three Policy' texts embodied distinct moments and revealed tensions in the Policy definition, which can either strengthen a prescriptive trend of health as produce the debate about social determinants in an expanded conception of health. Politicizing such debate is the first step, at the risk of stating a policy that, mainly, blames and responsible individual.

KEYWORDS Health promotion; Health policy; Policy making.

1 Ministério da Saúde,

Secretaria Executiva -

Brasília (DF), Brasil.

patricia.ferras@saude.gov.br

2 Fundação Oswaldo Cruz

(Fiocruz), Escola Nacional de Saúde Pública Sergio

Arouca (Ensp) - Rio de

Janeiro (RJ), Brasil.

twargas@ensp.fiocruz.br 


\section{Introdução}

'Promoção da saúde' é uma terminologia antiga e presente no campo da saúde pública desde seus primórdios. Entre os séculos XVIII e XIX, médicos como Virchow, Neumann, Rumsay e outros empregavam o termo para propor ações com o objetivo de evitar a propagação de doenças, estabelecendo relações entre processos de adoecimento e morte e as condições econômicas e sociais de determinados grupos (ROSEN, 1980).

Com a descoberta do micróbio, e a contribuição de bacteriologistas como Koch e Pasteur no final do século XIX, consolidou-se o modelo unicausal, com o entendimento de que para cada doença específica havia um agente específico. $\mathrm{O}$ desenvolvimento do modelo representou uma profunda transformação no campo e contribuiu para a hegemonia do paradigma bacteriológico (BUSS; PELLEGRINI FILHO, 2007), favorecendo a abordagem individual e mantendo a dimensão social em segundo plano (ALMEIDA FILHO, 1986). Neste contexto, o argumento em torno da promoção perdeu espaço e instaurou-se o dilema ainda atual: o objeto de intervenção da saúde pública devem ser as doenças específicas ou ter uma atuação mais ampla em torno das condições de vida e modos de viver? (BARATA, 2005).

Em 1936, John Ryle retoma a discussão de Virchow sobre a promoção da saúde, indicando a insuficiência das reformas sanitárias nos países enquanto persistisse a situação de pobreza. Nesse ano, lança um livro com a sistematização do paradigma da História Natural da Doença (HND), correlacionando a dimensão ambiental com as teorias microbianas (TERRIS; CARVALHO, 2005).

Anos depois, em 1958, Leavell \& Clark revisitam a discussão da HND e desenvolvem uma tese com enfoque no indivíduo e contexto, onde descrevem a evolução das enfermidades e defendem apontando diferentes métodos de prevenção e controle a partir do conhecimento do curso de desenvolvimento de uma doença. No modelo, a prevenção se constitui na ação antecipada com o objetivo de interceptar ou anular a ação de uma doença e deve ocorrer nos períodos de pré-patogênese e patogênese, em três níveis de prevenção: primária, secundária e terciária. A promoção da saúde estaria inserida na prevenção primária, na pré-patogênese, pressupondo medidas em relação à moradia, escolas, áreas de lazer, alimentação adequada, educação (ROUQUAYROL; ALMEIDA FILHO, 1999). Assim, a promoção da saúde ganha contornos mais específicos, com estratégias e ações junto aos grupos sociais e com o foco na doença. E o modelo passa a sustentar no âmbito da prática médica a medicina preventiva.

A medicina preventiva reforçava o entendimento da doença nas relações mais diretas de causalidade e, apesar de considerar as variáveis sociais, não as tratava como determinantes ou condicionantes relacionados ao modelo de Estado (BARATA, 2005). A inflexão para uma discussão sobre a determinação social da doença associada à visão de condições estruturais que afetam a vida de uma coletividade ocorrerá nos anos 1970, quando a desigualdade se acentua em muitos países e o modelo de proteção do Estado adotado pelos países avançados colocava-se em questão.

A década de 1970 foi fundamental para disparar o debate sobre a promoção da saúde, concebida como estratégia para o enfrentamento das questões da saúde para além da assistência médica, seja para diminuição de gastos ou para minorar questões mais amplas. O fato é que, nesse momento, a promoção é proposta para agir sobre os modos de vida da população, associando a ocorrência de enfermidades aos comportamentos de risco, cuja base é a discussão do Informe Lalonde, publicado no Canadá em 1974, e o relatório 'Healthy people', publicado nos Estados Unidos em 1979 (FERREIRA; CASTIEL; CARDOSO, 2011).

A década de 1980 foi decisiva para afirmação do movimento internacional em torno da promoção da saúde. O principal evento da década e marco para a mudança do paradigma do movimento de promoção da saúde 
foi a I Conferência Internacional sobre Promoção da Saúde, em Ottawa, Canadá, em novembro de 1986. O relatório final divulgou a proposta de uma 'Nova Promoção da Saúde', trazendo um 'novo olhar' baseado na ótica dos determinantes e condicionantes da saúde. Tal olhar se constituiu num avanço no debate na medida em que passava a entender que para promover saúde era necessário ir além de propor a alteração do estilo de vida, já que este se reportava exclusivamente à esfera individual, devendo-se trabalhar na perspectiva do conceito ampliado de saúde. $O$ documento produzido na conferência ficou conhecido como 'Carta de Ottawa' e tornou-se o principal documento de referência para a promoção da saúde elaborado em consonância com os princípios apresentados pela Organização Mundial da Saúde (OMS).

Assiste-se, portanto, nos anos 1980, uma série de transformações no debate da promoção da saúde, que passou a ser disseminada por todo o mundo, trazendo em seu bojo diferentes perspectivas e configurando um campo de tensão entre autores com diferentes visões acerca do seu uso. A mudança de paradigma em torno do que se entendia por promoção da saúde inaugurou o dilema que se pode resumir na tensão entre dois grandes blocos nesse campo: um que mais se aproxima da concepção de Lalonde, focada na abordagem comportamental, no estilo de vida individual, e outro que amplia seu foco além do estilo de vida, vinculando-se à discussão dos determinantes sociais da saúde e tendo como marco Ottawa (SILVA; BAPTISTA, 2014).

Na década de 1990, há uma maior divulgação e oferta do movimento como estratégia de política pública para que os países redesenhassem seus modelos de assistência à saúde, com diversas conferências que reafirmavam os conceitos e produziam documentos norteadores. Esse período é também marcado pela presença das relações internacionais, com maior força da globalização e aparente diluição das fronteiras mais rígidas entre países.
No Brasil, o debate em torno da promoção da saúde inicia-se numa crítica ao modelo da medicina preventiva e da HND na década de 1970. Arouca (1975), na tese 'O dilema preventivista', apresenta os limites do modelo, concluindo que a medicina preventiva representava uma simplificação do real e um afastamento das determinações, pois desconsiderava as condições inerentes ao processo saúde-doença, atendo-se apenas a uma dimensão no cuidado à saúde em detrimento da discussão da causa das causas.

A crítica de Arouca e de tantos outros pensadores da América Latina nessa década (como Breilh, Donnangelo, Tambellini, Possas, Laurell) mobilizava uma leitura abrangente sobre os determinantes sociais, remetendo ao debate sobre a política de proteção adotada pelos Estados, os direitos sociais e a tensa relação entre política econômica e política social.

Durante os anos 1980, o debate brasileiro manteve-se distante da discussão da promoção da saúde como movimento internacional, pois havia o interesse claro em aprofundar a discussão da causa das causas e a determinação social da doença, não havendo espaço para o foco específico na discussão da promoção da saúde (SILVA; BAPTISTA, 2014).

Nos anos 1990, a promoção da saúde começou a ocupar espaço no debate político-institucional brasileiro, mas somente no final da década inicia-se um movimento concreto de institucionalização da promoção da saúde como política nacional, com a formalização da cooperação com o Programa das Nações Unidas para o Desenvolvimento (PNUD) (BUSS; CARVALHO, 2009). O debate em torno da definição da Política Nacional de Promoção da Saúde (PNPS) transcorreu durante os anos 2000, sendo um primeiro documento de discussão apresentado em 2002, sua institucionalização aprovada em 2006 e sua redefinição, em 2014.

Este artigo discute os argumentos presentes nos diferentes textos da PNPS apresentados no contexto brasileiro a partir dos anos 
2000 com o objetivo de reunir elementos para a compreensão de como a promoção da saúde ganhou institucionalidade e entrou na agenda governamental, despertando a atenção e o interesse dos formuladores de políticas e colocando em discussão a perspectiva de promoção da saúde adotada na política nacional.

O texto está estruturado em quatro partes. Na primeira, abordam-se os caminhos da pesquisa. Em seguida, apresenta-se o contexto dos anos 2000 e as interfaces com a discussão da PNPS no Brasil. Na terceira parte discute-se os argumentos que fundamentaram os diferentes documentos da PNPS apresentados nos anos 2000. Na última parte sintetizam-se os principais achados e desdobramentos dessa política para o sistema de saúde brasileiro com questões pertinentes ao debate da promoção da saúde na atualidade.

\section{Caminhos da pesquisa}

O estudo assume a política como um processo dinâmico que se constitui a partir da mediação de conflitos, disputas e interesses dos atores e grupos envolvidos no debate. Assim, parte-se do entendimento que o documento de uma política é, em geral, a expressão de um processo de negociação e consenso em torno de uma questão, refletindo o contexto em que se insere (BAPTISTA; MATTOS, 2011).

Para a análise de como a Política Nacional de Promoção da Saúde ganhou institucionalidade e entrou na agenda governamental no Brasil, duas estratégias de pesquisa foram importantes: a revisão bibliográfica e a revisão e análise documental.

A revisão bibliográfica foi fundamental para o reconhecimento das 'construções históricas' e sentidos de promoção da saúde enunciados nos textos oficiais e possibilitou a identificação da rede de atores e instituições que participaram do debate no Brasil. Nesta revisão, foi importante considerar os textos e materiais gerados em seminários, oficinas de trabalho da Associação Brasileira de Pós-Graduação em Saúde Coletiva (Abrasco), bem como as sínteses das conferências nacionais e internacionais de promoção da saúde.

Já a revisão de documentos, foi a estratégia central do estudo. Identificaram-se três documentos de base para análise da política: o documento para discussão de 2002, com a primeira formulação de uma PNPS no Brasil, e os documentos oficiais da PNPS de 2006 e 2014, editados pelo Ministério da Saúde (MS) e amplamente divulgados. A análise dos diferentes textos da política (2002, 2006 e 2014) possibilitou o reconhecimento das estruturas, convergências e divergências entre os documentos, bem como os principais argumentos presentes em cada contexto.

Todo o material de pesquisa foi analisado a partir de categorias temáticas identificadas no processo de leitura dos documentos. As referências bibliográficas foram fundamentais no contraponto aos argumentos e visões expressos nas diferentes fontes.

\section{O contexto para construção da PNPS}

A promoção da saúde ganhou espaço no debate nacional no final dos anos 1990 e foi editada como política pela primeira vez no ano de 2006.

O legado dos anos 2000 está na compreensão do que foi a década de 1990, permeada de contradições, avanços e rupturas com a condução política da década anterior, refletindo os embates decorrentes da crise do Estado e a captura por interesses privados e pela globalização. Fagnani (2005) destaca que, durante a década de 1990, o gasto social brasileiro passou a ser o 'grande vilão' da economia, da estabilidade da moeda e das contas públicas. Uma solução indicada para combater a desigualdade estava em deslocar os recursos de programas universais para programas centrados na transferência de renda. Assim, para o autor, a partir de 1990, assistiu-se a 
uma contínua tentativa para fazer regredir a cidadania conquistada, negando direitos constitucionais e reduzindo a questão social aos 'mais pobres dentre os pobres'.

Ao final da década, é possível perceber uma mudança de rota. $O$ controle da inflação já não era mais a única política a ser mantida; pode-se falar de investimento e novas políticas. É nesta oportunidade que surgem ou que se fortalecem muitas políticas específicas na saúde - saúde mental, Programa Saúde da Família (PSF), saúde bucal, transplantes, saúde do adolescente, renais e tantas outras. A promoção da saúde encontra nesse cenário um terreno fértil, favorável para sua disseminação como estratégia, numa combinação de diretrizes com mudanças no modelo de atenção.

No ano de 1997, o MS sofreu uma reestruturação, sendo criadas novas secretarias e áreas, dentre elas a Secretaria de Políticas de Saúde (SPS). O interesse era constituir, na saúde, um espaço privilegiado de atuação política, uma 'vitrine da política de governo' cuja principal estratégia era a municipalização, com prioridade para ações de promoção da saúde e prevenção de doenças, enfatizadas pela constituição do Piso da Atenção Básica (PAB) e estímulos ao Programa Saúde da Família e Programa de Agentes Comunitários (PSF/Pacs) (BAPTISTA, 2003). No âmbito da SPS, a promoção da saúde tornou-se um dos três eixos fundamentais para a formulação de políticas.

Em 1998, o MS, em cooperação com o PNUD, desenvolveu o Projeto Promoção da Saúde em um Novo Modelo de Atenção, cujo objetivo era implementar e consolidar a promoção da saúde no Brasil a partir da operacionalização dos cinco campos da Carta de Ottawa, além de institucionalizar uma política nacional (BRASIL, 2002B).

No ano de 2002, o MS apresentou um documento para discussão intitulado 'Política Nacional de Promoção da Saúde' (BRASIL, 2002A). O documento não foi encaminhado como política, mas já apresentava uma proposta concreta de formulação para a política nacional, aprofundando as bases conceituais da promoção da saúde a partir do resgate histórico da reforma sanitária, seus princípios e valores.

Em 2003, teve início uma nova gestão ministerial com o início do governo Lula. Mudanças são implementadas na estrutura do MS. A SPS foi extinta e a área da promoção da saúde, antes inserida no contexto da SPS, passou a estar vinculada à Secretaria Executiva (SE) do MS, com a orientação de Gastão Wagner de Souza Campos, então secretário executivo. A vinculação à $\mathrm{SE}$ significava a aposta de tornar a política de promoção da saúde transversal às ações das demais secretarias, entendendo que a SE deveria operar como um dispositivo integrador da agenda de vários segmentos sanitários. $\mathrm{O}$ conceito ampliado de saúde era o ponto de comunicação entre a promoção da saúde e o Sistema Único de Saúde (SUS), tratando-se de um compromisso ético com a integralidade e a gestão participativa que poderia operar na indissociabilidade entre a clínica e a promoção da saúde e entre necessidades sociais e ações do Estado (CAMPOS; BARROS; CASTRO, 2004).

No fim de 2004, novas mudanças ocorrem no MS, em razão das quais a área de promoção da saúde e o debate da política foram deslocados para a Secretaria de Vigilância em Saúde (SVS), subordinada à Coordenação-Geral de Doenças e Agravos Não-Transmissíveis (CGDANT). Com a mudança, perdeu-se a ênfase na proposta de uma política transversal tal como pensada no âmbito da SE.

Neste contexto, importante movimento na direção da construção da PNPS foi a instituição do Comitê Gestor da PNPS (CGPNPS) em 2005, com o objetivo de consolidar a proposta de uma PNPS e articular e integrar a promoção da saúde no SUS. Inicialmente, a composição do Comitê pressupôs apenas adotar representantes do setor saúde, da esfera federal. Somente em 2007 foram incorporados 
representantes do Conselho Nacional de Secretários de Saúde (Conass) e do Conselho Nacional de Secretarias Municipais de Saúde (Conasems) no Comitê Gestor.

Outra instituição importante no debate para o desenvolvimento da política nesse momento foi a Abrasco, que iniciou as discussões relativas ao tema no ano de 2002 . O Grupo Temático (GT) da promoção da saúde foi formalmente instituído no ano de 2005. Formou-se, também nesse período, uma rede de atores, entre técnicos e consultores relacionados ao MS, professores e pesquisadores que atuavam nas universidades e instituições de pesquisa e que pressionavam para a formulação da política.

A discussão da política avançou e a promoção da saúde apareceu em documentos e políticas editadas a partir de então. Ressalte-se que o período compreendido entre meados de 2005 e final de 2006 foi marcado por um longo período de transitoriedade no MS. Houve, por um lado, continuidade e a institucionalização de diversas políticas, editadas por secretarias diferentes, mas também ocorreu a falta de integração e contradições entre as diretrizes das políticas, o que refletiu especificamente no entendimento do conceito de promoção da saúde empregado. Um bom exemplo dessas contradições e dificuldades para interação das áreas e secretarias do MS se expressam nos documentos do Pacto pela Saúde e na Política Nacional de Atenção Básica (PNAB). No Pacto, a promoção da saúde apresentou-se focada em ações restritivas, na perspectiva de 'internalizar a responsabilidade individual' na prática de atividade física, combate ao tabagismo e alimentação saudável (BRASIL, 2006), na PNAB, a promoção da saúde é entendida como área estratégica para a operacionalização da política.

\section{Os diferentes documentos da política e os sentidos de promoção da saúde}

Apesar da ordem cronológica dos acontecimentos em torno da construção de um texto para a conformação da PNPS, não houve a continuidade em sua redação. $\mathrm{Na}$ análise dos documentos de 2002, 2006 e 2014, é possível perceber pontos de convergência, divergência e contradições em torno do que se pretende por em prática como política de promoção da saúde. Não se trata de eleger o melhor documento nem mesmo de estabelecer julgamentos; o objetivo da análise volta-se para o entendimento dos textos como processos políticos, atravessados pelos contextos e possibilidades reais de cada tempo, sofrendo interferências dos atores políticos e das arenas em que se conformaram, aproveitando as oportunidades para a entrada na agenda de governo e para institucionalização como política nacional.

O documento para discussão da PNPS apresentado em 2002 não foi encaminhado como política de governo, mas sua estrutura e os argumentos que apresenta justificam sua análise como documento de política, além de expressar o debate nesse período. $\mathrm{O}$ texto inicia com uma citação de Paulo Freire e estabelece as interseções entre o movimento internacional da promoção da saúde e a realidade brasileira, destacando o processo de redemocratização e a constituição das bases operacionais para implementação das legislações existentes. Com isso, abandona o tom de recomendação internacional para reforçar o reconhecimento das necessidades locais com proposições acerca do fazer saúde.

O documento recupera o compromisso que os países assumiram de abordar os determinantes básicos e os pré-requisitos para a saúde e destaca que a promoção da saúde deveria desencadear um processo amplo, com parcerias, atuações intersetoriais e participação popular, numa reflexão sobre o objeto saúde, como um conceito em construção, que coloca em discussão os problemas impostos pela realidade sanitária, exigindo um olhar além da doença.

O conceito de autonomia utilizado no documento também está referido a Paulo Freire, destacando a afetividade, a amorosidade, a 
capacidade criadora e a busca da felicidade como igualmente relevantes e indissociáveis das demais dimensões humanas. Dessa forma, a promoção da saúde é indicada como vivencial e colada ao sentido de viver e aos saberes acumulados, tanto pela ciência como pelas tradições culturais locais e universais. Ou seja, reforça o reconhecimento de que as ações de promoção da saúde apresentam um 'componente regulatório', mas faz a aposta de que tais ações podem ser mais indutoras e estar a serviço do desenvolvimento humano e do processo de emancipação da nação, com mobilização comunitária e intimamente vinculada à concepção de território vivo, de Milton Santos.

O documento afirma que a promoção da saúde não deveria ser mais um nível de atenção e nem deveria corresponder a ações anteriores à prevenção, colocando-se o desafio de reorientar os serviços de saúde para superar a fragmentação do assistir à doença, em direção à atenção integral. Com isso, a aposta refere-se às estratégias intersetoriais para definição de problemas prioritários, buscando a integração e implementação pelos municípios.

O documento para discussão de 2002 não apresenta autoria. Trata-se de um texto que discute em profundidade a temática da promoção, numa interface com as ciências humanas e sociais. $\mathrm{O}$ uso de um vocabulário diferenciado e crítico chama a atenção. E, apesar de enunciar-se como um documento propositivo da Política, não apresenta estratégias ou ações para operacionalização de uma política.

O documento aprovado em 2006 segue outro caminho discursivo em relação ao de 2002. Foi assinado pelo Ministro José Agenor, que apresenta um panorama geral da promoção da saúde no campo da saúde, recuperando a Agenda de Compromisso pela Saúde definida pelo MS em 2005 e o Pacto pela Saúde de 2006. O Ministro identifica como grande desafio para a PNPS o estabelecimento de um diálogo entre as diversas áreas do setor saúde, incluindo o setor privado, não governamental e outros setores do governo. Com tal ênfase, a política ainda define-se como uma proposta de caráter transversal e intersetorial, numa discussão próxima à que se realizava desde 2003 no âmbito da SE.

Na PNPS de 2006, há um esforço em conceituar a promoção da saúde a partir dos marcos legais das cartas da promoção internacionais. Assim, por meio de um panorama geral, a PNPS localiza o debate como estratégia de articulação transversal, com estreita relação com a vigilância em saúde, privilegiando o bem de todos e a construção de uma sociedade solidária, cujo objetivo geral se concentra em torno da redução de vulnerabilidade e riscos à saúde e da qualidade de vida. Nesse ponto, a discussão se aproxima da vigilância em saúde e, portanto, do conceito de prevenção.

A estrutura do documento reforça uma preocupação com a definição de estratégias de ação que sejam passíveis de acompanhamento, com proposições e compromissos de gestão que reforçam a promoção da saúde de caráter regulatório, focada na mudança dos estilos de vida e na redução de fatores de risco, ainda que acompanhada da perspectiva do conceito ampliado de saúde.

A ênfase discursiva do documento define estratégias prioritárias que reforçam uma dada perspectiva de promoção da saúde, que visa ao controle e prevenção de doenças com ações que pautam hábitos e estilos de vida, como: alimentação saudável, prática corporal, atividade física, controle do tabagismo, redução da morbimortalidade em decorrência do uso abusivo de álcool e outras drogas, redução da morbimortalidade por acidentes de trânsito, prevenção da violência e cultura da paz e promoção do desenvolvimento sustentável.

O documento de 2006 recorreu exclusivamente a textos nacionais oficiais, sem qualquer menção ao documento produzido em 2002. É um documento que adota o discurso oficial, com objetivos e ações que não condizem com a dimensão complexa ora apresentada no debate da política, mantendo-se restrito ao debate das estratégias para combate dos 
determinantes sociais da saúde. Evidencia-se nos documentos e bibliografia que a política mediou diferentes interesses e grupos do MS e acabou conformando um texto com diferentes enfoques, num consenso possível.

Em 2014, o documento da PNPS de 2006 passou por um processo de redefinição, que, para Rocha et al. (2014), foi resultado de 'múltiplos movimentos simultâneos' envolvendo o GT promoção da saúde da Abrasco, MS, Organização Pan-Americana da Saúde (Opas) e o Comitê Gestor da PNPS. Ampliouse o processo de participação em relação a 2002 e 2006, envolvendo e mobilizando diferentes atores em torno da revisão da política.

A redefinição da PNPS de 2014 (BRASIL, 2014), assinada pelo então ministro da saúde Arthur Chioro, justificou-se no próprio texto pela necessidade de incrementar as ações de promoção da saúde no território, garantindo sua consonância com os princípios e diretrizes do SUS. O texto apresenta esse esforço de aproximação com os diferentes movimentos da promoção fazendo menção nas considerações iniciais a portarias e decretos da saúde publicados de 2007 a 2012.

Toda essa fundamentação legal imprime ao documento um tom de articulação e íntima relação com os pressupostos das demais políticas de saúde que se destacam nos anos 2000, as quais precisam se debruçar sobre a lógica de organização do SUS com um olhar voltado para o território e a partir dele, considerando a regionalização e um conjunto claro de dispositivos de financiamento e cogestão.

$\mathrm{O}$ enunciado da política fundamenta-se no conceito ampliado de saúde e nos referenciais teóricos da promoção da saúde, buscando a produção da saúde nos âmbitos individual e coletivo, enfatizando a necessidade de articulação intra e intersetorial e da Rede de Atenção à Saúde (RAS) com as demais redes de proteção, privilegiando a participação e o controle social.

Dentre as mudanças, o documento estabelece um conjunto de valores considerados fundantes no processo de efetivação da política, quais sejam: solidariedade, felicidade, ética, respeito à diversidade, humanização, corresponsabilidade, justiça social e inclusão social. É interessante destacar o argumento da 'felicidade', que, no conjunto de argumentos de 2002, já era tratada como relevante e indissociável das demais dimensões humanas, mas não fez parte do texto de 2006, sendo retomada em 2014.

O objetivo geral da PNPS continua em torno da redução de vulnerabilidade e riscos à saúde e da qualidade de vida, no sentido da promoção da equidade e da melhoria das condições e modos de viver. Dentre os temas prioritários, foram mantidos aqueles tratados como ações estratégicas na PNPS de 2006, tais como: alimentação, atividades físicas, tabagismo, uso abusivo de álcool e outras drogas; cultura da paz e desenvolvimento sustentável. A novidade decorreu do conceito ampliado de promoção da mobilidade segura e da formação e educação permanente, embora ambos, em alguma medida, também já estivessem presentes em 2006.

O documento finaliza com a divisão de competências gerais e privativas de cada esfera de governo e com a definição sobre o financiamento, indicando que este deve ser objeto de pactuação prévia na Comissão Intergestores Tripartite (CIT). Diferentemente dos documentos de 2002 e 2006, o texto de 2014 apresenta-se num formato mais rígido de lei, não fazendo menção a referências bibliográficas ou autoria.

Para melhor compreensão dos diferentes enfoques nos documentos, elaborou-se um quadro comparativo dos documentos de 2002, 2006 e 2014, onde estabeleceram-se eixos de análise para aprofundar o debate, sem a pretensão de esgotá-los (quadro 1). Trata-se de visualizar as transformações ocorridas ao longo da produção do texto da política, não somente do ponto de vista de sua redação, mas dos sentidos em disputa que definiram as escolhas conceituais da perspectiva que prevaleceu na PNPS em 2014. 
Quadro 1. Documentos da Política Nacional de Promoção da Saúde (trechos dos documentos - página) - 2002, 2006, 2014

\begin{tabular}{|c|c|c|c|}
\hline Argumentos & 2002 & 2006 & 2014 \\
\hline Objetivos & $\begin{array}{l}\text { - Tornar as condições políticas, } \\
\text { econômicas, sociais, culturais, } \\
\text { ambientais e de conduta favoráveis } \\
\text { à saúde dos indivíduos e de suas } \\
\text { comunidades no pressuposto ético de } \\
\text { defesa da vida e do desenvolvimento } \\
\text { humano; } \\
\text { - Reduzir as desigualdades quanto } \\
\text { ao acesso às oportunidades para o } \\
\text { desenvolvimento máximo do potencial } \\
\text { de saúde; } \\
\text { - Qualificar o Sistema Único de } \\
\text { Saúde na perspectiva da promoção } \\
\text { da saúde como enfoque que } \\
\text { permeie suas políticas e ações } \\
\text { e favoreça sua sustentabilidade, } \\
\text { por meioda melhor efetividade na } \\
\text { abordagem dos problemas de saúde e } \\
\text { redirecionamento de recursos. }\end{array}$ & $\begin{array}{l}\text { - Geral: Promover a qualidade de vida e } \\
\text { reduzir vulnerabilidade e riscos à saúde } \\
\text { relacionados aos seus determinantes } \\
\text { e condicionantes - modos de viver, } \\
\text { condições de trabalho, habitação, } \\
\text { ambiente, educação, lazer, cultura, acesso } \\
\text { a bens e serviços essenciais. } \\
\text { - } 12 \text { objetivos específicos. }\end{array}$ & $\begin{array}{l}\text { - Geral: Promover a equidade e a melhoria } \\
\text { das condições e modos de viver, ampliando } \\
\text { a potencialidade da saúde individual e da } \\
\text { saúde coletiva, reduzindo vulnerabilidades } \\
\text { e riscos à saúde decorrentes dos } \\
\text { determinantes sociais, econômicos, } \\
\text { políticos, culturais e ambientais. } \\
\text { - } 13 \text { objetivos específicos. }\end{array}$ \\
\hline $\begin{array}{l}\text { Reforma Sanitária } \\
\text { e Conceito } \\
\text { Ampliado de } \\
\text { Saúde }\end{array}$ & $\begin{array}{l}\text { - O Brasil vem construindo a } \\
\text { partir de sua reforma sanitária um } \\
\text { extraordinário processo de reforma do } \\
\text { Estado no setor (5) } \\
\text { - Políticas de promoção da } \\
\text { saúde devem contribuir para o } \\
\text { aprofundamento das promessas da } \\
\text { reforma sanitária brasileira (10) } \\
\text { - Recolocar o conceito amplo e positivo } \\
\text { de saúde, como valor de vida (27) }\end{array}$ & $\begin{array}{l}\text { - (8a CNS, 1986) Era um momento chave } \\
\text { do movimento da Reforma Sanitária } \\
\text { brasileira (10) } \\
\text { - Na perspectiva ampliada de saúde, } \\
\text { como definida no âmbito do movimento } \\
\text { da Reforma Sanitária Brasileira (10) } \\
\text { - Na base do processo de criação do SUS } \\
\text { encontram-se: o conceito ampliado de } \\
\text { saúde [...] (10) }\end{array}$ & $\begin{array}{l}\text { - A PNPS traz em sua base o conceito } \\
\text { ampliado de saúde e o referencial teórico } \\
\text { da promoção da saúde (2) }\end{array}$ \\
\hline Autonomia & $\begin{array}{l}\text { - Trabalha com o princípio da } \\
\text { autonomia dos indivíduos e das } \\
\text { comunidades (9) } \\
\text { - Novas agendas como o estímulo à } \\
\text { autonomia dos indivíduos (10) } \\
\text { - Promover saúde é educar para a } \\
\text { autonomia como construído por Paulo } \\
\text { Freire (13) } \\
\text { - Reorientação do cuidado na } \\
\text { perspectiva do respeito à autonomia } \\
\text { (36) }\end{array}$ & $\begin{array}{l}\text { - Ampliar a autonomia e a } \\
\text { corresponsabilidade de sujeitos e } \\
\text { coletividades, inclusive o poder publico } \\
\text { (17) } \\
\text { - Redução de danos pelo consumo de } \\
\text { álcool e outras drogas que envolvam a } \\
\text { corresponsabilização e autonomia da } \\
\text { população (37) }\end{array}$ & $\begin{array}{l}\text { - Autonomia, que se refere à identificação } \\
\text { de potencialidades e ao desenvolvimento } \\
\text { de capacidades (3) } \\
\text { - Estimulo à pesquisa, à produção e à } \\
\text { difusão de experiências, conhecimentos } \\
\text { e evidências que apoiem a tomada de } \\
\text { decisão, a autonomia (4) } \\
\text { - Autonomia de sujeitos e coletividades (5) } \\
\text { - Corresponsabilização e autonomia da } \\
\text { população (8) }\end{array}$ \\
\hline Emancipação & $\begin{array}{l}\text { - Embora tenha um componente } \\
\text { regulatório, devem ser mais indutoras } \\
\text { e estar a serviço do desenvolvimento } \\
\text { humano e do processo de } \\
\text { emancipação da nação (14) } \\
\text { - Os países periféricos e semi- } \\
\text { periféricos como o Brasil, devem } \\
\text { se debruçar em discutir e construir } \\
\text { alternativas ao desenvolvimento, } \\
\text { sustentadas numa lógica ecológica e } \\
\text { emancipatória (16) }\end{array}$ & - Não utiliza o termo & $\begin{array}{l}\text { - Educação e formação como incentivos } \\
\text { à atitude permanente de aprendizagem } \\
\text { sustentada em processos pedagógicos } \\
\text { problematizadores, dialógicos, libertadores, } \\
\text { emancipatórios e críticos (7) }\end{array}$ \\
\hline
\end{tabular}




\begin{tabular}{|c|c|c|c|}
\hline Argumentos & 2002 & 2006 & 2014 \\
\hline Participação & $\begin{array}{l}\text { - Promover saúde também é aceitar } \\
\text { o imenso desafio de desencadear um } \\
\text { processo amplo que inclui a articulação } \\
\text { de parcerias, atuações intersetoriais e } \\
\text { participação popular (12) } \\
\text { - A participação da população não } \\
\text { somente nas instâncias formais, mas } \\
\text { em outros espaços constituídos por } \\
\text { atividades sistemáticas e permanentes } \\
\text { (19) } \\
\text { - Ampliar a participação social e } \\
\text { comunitária nas decisões de gestão, } \\
\text { no acompanhamento e controle das } \\
\text { políticas (28) } \\
\text { - Incentivar a participação comunitária } \\
\text { nas decisões da gestão, reforçando o } \\
\text { papel do controle social (38) } \\
\text { - As evidências mostram que a } \\
\text { participação em grupos exerce um } \\
\text { fator protetor para a saúde (38) }\end{array}$ & $\begin{array}{l}\text { - Fortaleçam o protagonismo dos } \\
\text { cidadãos em sua elaboração e } \\
\text { implementação, ratificando os preceitos } \\
\text { constitucionais de participação social (11) } \\
\text { - A criação de mecanismos de } \\
\text { mobilização e participação como os } \\
\text { vários movimentos e grupos sociais (11) } \\
\text { - A saúde, como produção social de } \\
\text { determinação múltipla e complexa, exige } \\
\text { a participação ativa de todos os sujeitos } \\
\text { envolvidos em sua produção (12) } \\
\text { - Mecanismos que reduzam as } \\
\text { situações de vulnerabilidade, defendam } \\
\text { radicalmente a equidade e incorporem } \\
\text { a participação e o controle sociais na } \\
\text { gestão das políticas públicas (12) } \\
\text { - Respeito às diversas identidades } \\
\text { culturais nos canais efetivos de } \\
\text { participação no processo decisório (27) }\end{array}$ & $\begin{array}{l}\text { - Articular suas ações com as demais redes } \\
\text { de proteção social, com ampla participação } \\
\text { e controle social (2) } \\
\text { - Incentivar à gestão democrática, } \\
\text { participativa e transparente para } \\
\text { fortalecimento da participação (4) } \\
\text { - Contribuir para a adoção de práticas } \\
\text { sociais e de saúde centradas na equidade, } \\
\text { na participação e no controle social (4) } \\
\text { - Fortalecer a participação e o controle } \\
\text { social e as instâncias de gestão } \\
\text { democrática e participativa (9) } \\
\text { - Identificar e promover canais de } \\
\text { participação no processo decisório (12) } \\
\text { - Promover a participação e o controle } \\
\text { social e reforçar as ações comunitárias de } \\
\text { promoção da saúde nos territórios (12) }\end{array}$ \\
\hline Empoderamento & - Não utiliza o termo & $\begin{array}{l}\text { - Fortalecer a participação social como } \\
\text { fator fundamental na consecução de } \\
\text { resultados de promoção da saúde, em } \\
\text { especial a equidade e o empoderamento } \\
\text { individual e comunitário (19) } \\
\text { - Estimular ações de empoderamento do } \\
\text { consumidor para o entendimento e uso } \\
\text { prático da rotulagem geral e nutricional } \\
\text { dos alimentos (31) }\end{array}$ & $\begin{array}{l}\text { - Empoderamento, que se refere ao } \\
\text { processo de intervenção que estimula os } \\
\text { sujeitos e coletivos a adquirirem o controle } \\
\text { das decisões e das escolhas de modos de } \\
\text { vida adequados às suas condições sócio- } \\
\text { econômico-culturais (3) } \\
\text { - Empoderamento coletivo e construção } \\
\text { compartilhada de ações de promoção da } \\
\text { saúde (4) } \\
\text { - Promover o empoderamento e a } \\
\text { capacidade para tomada de decisão (5) }\end{array}$ \\
\hline Intersetorialidade & $\begin{array}{l}\text { - Promover saúde também é aceitar } \\
\text { o imenso desafio de desencadear um } \\
\text { processo amplo que inclui a articulação } \\
\text { de parcerias, atuações intersetoriais e } \\
\text { participação popular (12) } \\
\text { - Outras medidas consideradas } \\
\text { de promoção de saúde, além de } \\
\text { caracterizar políticas intersetoriais, } \\
\text { representam tomada de posição da } \\
\text { Nação (22) } \\
\text { - Superar a fragmentação do Estado } \\
\text { moderno, admitindo a construção de } \\
\text { políticas e ações intersetoriais ( } 27 \text { ) } \\
\text { - Gestão intersetorial dos recursos } \\
\text { na abordagem dos problemas e } \\
\text { potencialidades em saúde (29) } \\
\text { - Aprofundamento do debate dos } \\
\text { problemas relacionados com a saúde } \\
\text { de forma intersetorial (41) }\end{array}$ & $\begin{array}{l}\text { - O compromisso do setor saúde na } \\
\text { articulação intersetorial é tornar cada } \\
\text { vez mais visível que o processo saúde- } \\
\text { adoecimento é efeito de múltiplos } \\
\text { aspectos (14) } \\
\text { - Mobilização intersetorial para a } \\
\text { proposição e elaboração de medidas } \\
\text { regulatórias que visem a promover a } \\
\text { alimentação saudável e reduzir o risco } \\
\text { de Doenças Crônicas Não Transmissíveis } \\
\text { (DCNT) (30) } \\
\text { - Incentivar articulaç̃̃es intersetoriais } \\
\text { para a melhoria das condições dos } \\
\text { espaços públicos para a realização de } \\
\text { práticas corporais e atividades físicas } \\
\text { (34) } \\
\text { - Promoção de discussões intersetoriais } \\
\text { que incorporem ações educativas à grade } \\
\text { curricular de todos os níveis de formação } \\
\text { (37) } \\
\text { - Estímulo à articulação intersetorial } \\
\text { que envolva a redução e o controle de } \\
\text { situações de abuso, exploração e turismo } \\
\text { sexual (38) }\end{array}$ & $\begin{array}{l}\text { - Caracterizando-se pela articulação e } \\
\text { cooperação intra e } \\
\text { intersetorial (2) } \\
\text { - Intersetorialidade, que se refere ao } \\
\text { processo de articulação de saberes, } \\
\text { potencialidades e experiências de sujeitos, } \\
\text { grupos e setores (3) } \\
\text { - Estímulo à cooperação e à articulação } \\
\text { intra e intersetorial (4) } \\
\text { - Organização dos processos de gestão e } \\
\text { planejamento } \\
\text { das variadas ações intersetoriais (4) } \\
\text { - Articulação e cooperação intra } \\
\text { e intersetorial, entendidas como } \\
\text { compartilhamento de planos, metas, } \\
\text { recursos e objetivos comuns (7) } \\
\text { - Orientar ações integradas e intersetoriais } \\
\text { nos territórios (8) } \\
\text { - Promover a articulação intra e } \\
\text { intersetorial para apoio à } \\
\text { implantação e implementação da PNPS (11) }\end{array}$ \\
\hline
\end{tabular}




\begin{tabular}{|c|c|c|c|}
\hline Argumentos & 2002 & 2006 & 2014 \\
\hline Vulnerabilidade & - Não utiliza o termo & $\begin{array}{l}\text { - Visando a romper com a excessiva } \\
\text { fragmentação na abordagem do } \\
\text { processo saúde-adoecimento e reduzir a } \\
\text { vulnerabilidade, os riscos e os danos que } \\
\text { nele se produzem (15) } \\
\text { - Promover a qualidade de vida e } \\
\text { reduzir vulnerabilidade e riscos à saúde } \\
\text { relacionados aos seus determinantes e } \\
\text { condicionantes (17) } \\
\text { - Ofertar práticas corporais e atividade } \\
\text { físicas voltadas tanto para a comunidade } \\
\text { como um todo como para grupos } \\
\text { vulneráveis (33) } \\
\text { - Apoio à restrição de acesso a bebidas } \\
\text { alcoólicas de acordo com o perfil } \\
\text { epidemiológico de dado território, } \\
\text { protegendo segmentos vulneráveis (37) }\end{array}$ & $\begin{array}{l}\text { - Reduzir a vulnerabilidade e os riscos } \\
\text { à saúde vinculados aos determinantes } \\
\text { sociais (4) } \\
\text { - Reduzindo vulnerabilidades e riscos à } \\
\text { saúde decorrentes dos determinantes } \\
\text { sociais, econômicos, políticos, culturais e } \\
\text { ambientais (4) } \\
\text { - Fomentar discussões sobre modos de } \\
\text { consumo e produção que [...] aumentem } \\
\text { vulnerabilidades e riscos à saúde (5) } \\
\text { - Construir mecanismos de identificação } \\
\text { das potencialidades e das vulnerabilidades } \\
\text { (9) }\end{array}$ \\
\hline Evidências & $\begin{array}{l}\text { - Evidências mostram que a saúde } \\
\text { está muito mais relacionada ao modo } \\
\text { de viver das pessoas do que à ideia } \\
\text { hegemônica da sua determinação } \\
\text { genética e biológica ( } 8 \text { ) } \\
\text { - Podemos trabalhar com evidências na } \\
\text { promoção da saúde se ela se configura } \\
\text { como um campo de ações transversais } \\
\text { e multissetoriais, que mistura enfoques } \\
\text { e abordagens variadas (15) } \\
\text { - Um problema crônico em promoção } \\
\text { da saúde é a falta de evidências claras } \\
\text { de sua efetividade (25) } \\
\text { - As evidências mostram que a } \\
\text { participação em grupos exerce } \\
\text { um fator protetor para a saúde, } \\
\text { principalmente para os transtornos } \\
\text { mentais (38) }\end{array}$ & $\begin{array}{l}\text { - (Ao se retomarem as estratégias de } \\
\text { ação propostas pela Carta de Ottawa) } \\
\text { até o momento, o desenvolvimento de } \\
\text { estudos e evidências aconteceu, em } \\
\text { grande parte, vinculado às iniciativas } \\
\text { ligadas ao comportamento e aos hábitos } \\
\text { dos sujeitos (14) } \\
\text { - Nessa linha de intervenção } \\
\text { (comportamental) já é possível encontrar } \\
\text { um acúmulo de evidências convincentes, } \\
\text { que são aquelas baseadas em estudos } \\
\text { epidemiológicos demonstrativos (14) } \\
\text { - Desenvolver estudos e formular } \\
\text { metodologias capazes de produzir } \\
\text { evidências e comprovar a efetividade } \\
\text { de estratégias de práticas corporais e } \\
\text { atividades físicas (35) }\end{array}$ & $\begin{array}{l}\text { - Estimulo à pesquisa, à produção e à } \\
\text { difusão de experiências, conhecimentos } \\
\text { e evidências que apoiem a tomada de } \\
\text { decisão (4) }\end{array}$ \\
\hline
\end{tabular}

\section{Conclusão}

Identificamos nos três documentos da PNPS três momentos distintos, que, de alguma forma, se complementaram no decorrer da construção da política, denotando a busca pelo amadurecimento do debate.

O primeiro momento foi marcado pelo documento para discussão para uma PNPS de 2002 contendo a apresentação de conteúdo que defende o esforço de teorização do campo, trazendo para a agenda política a necessidade do desenvolvimento de ações, ainda que de maneira pouco clara até então, mas que evidencia a urgência e a importância da deflagração da temática na saúde coletiva no Brasil.

Sob pena de ser classificado como movimento capturado pela agenda internacional - até então bastante evidente e com um apelo claro para formalização como política pelos países -, o documento fez o esforço de teorização com base em autores, experiências e referências brasileiras, no sentido de demonstrar que tudo aquilo, embora presente na pauta internacional, encontrava-se intimamente vinculado aos preceitos da reforma sanitária, merecendo a atenção de sua institucionalização como política. 
O segundo momento, com a edição da PNPS de 2006, não parece guardar referência direta com o primeiro momento quanto à continuidade, já que se estabelecem sobre novas bases, com um forte componente de vigilância, não só em função de seu novo lugar na estrutura do MS (SVS), como também fundamentado em evidências que demonstravam a urgência no desenvolvimento de uma política que se mostrasse potente no enfrentamento dos agravos não transmissíveis. A agenda da promoção da saúde se organizou, portanto, em torno de um conjunto de questões estratégicas com um forte componente regulatório, focando na mudança dos estilos de vida e redução dos riscos, estando mais alinhada à orientação da SVS e devendo responder às situações identificadas pelos indicadores de saúde.

Assim, em 2006, há uma inflexão importante da política com maior operacionalização e definição de estratégias para execução da política. Enquanto o documento de 2002 apresentava uma reflexão conceitual, sem proposições claras e implementáveis, o documento de 2006 trazia proposições e perdia na profundidade do debate, com o intuito de responder a uma demanda clara de operacionalização da política.

O terceiro momento, identificado com o documento de 2014, parece unir algumas pontas, retomando e aprofundando os conceitos de promoção da saúde e, ao mesmo tempo, preservando os elementos já presentes e identificados como necessários na política de 2006 , tais como alimentação saudável, tabagismo, atividade física, por exemplo. Avança na interlocução com os demais dispositivos das políticas no âmbito do SUS, procurando não perder de vista a necessidade real de por em prática ações concretas.

O que está em questão em 2014 já não é mais a importância ou não da promoção da saúde e sim de que forma ela pode ou não contribuir de maneira articulada com os demais componentes e políticas de saúde.
Uma das grandes apostas do documento de 2014 está no destaque que se dá à intrassetorialidade, reconhecendo a complexidade do setor saúde e as disputas inerentes ao campo, alertando para o grande desafio de construção de consensos em seu interior, tanto quanto para fora dele, o que torna necessário assumir e empreender o debate da promoção da saúde com a saúde, no SUS.

Nesse sentido, a revisão do documento da política em 2014 trouxe de volta ao debate a discussão de valores, para a criação de um fazer que articule diferentes dimensões humanas, partindo de um reconhecimento ampliado de saúde, que já não se contenta com ações fragmentadas, isoladas e desconectadas entre si. A construção do documento envolveu diferentes atores, dos diferentes territórios, das diferentes regiões do Brasil, com o objetivo de desenvolver um debate articulado e consciente das novas necessidades do SUS, das demais políticas e formas de organização.

Trata-se de complementaridade, e não necessariamente de continuidade, o que reconhecemos na trajetória de tal política. Questões aparentemente superadas em 2002, ganham fôlego em 2006 e são retomadas em 2014, a exemplo da discussão de risco que foi retomada em seu sentido mais amplo e não mais com ênfase nos agravos, como em 2006.

Ainda assim, é preciso reconhecer que o debate da promoção da saúde apresenta uma trajetória discursiva que permite o uso polissêmico e vinculado aos interesses e pretensões de quem o empreende. É interessante observar que os dilemas desse campo, presentes desde o século XVIII, ainda são bastante atuais, em especial na tensão entre ações individuais e coletivas, exigindo reflexão constante sobre o sentido de promoção da saúde que se quer alcançar (FERREIRA; CASTIEL, 2009).

O debate brasileiro recente revela essas tensões, e a definição de uma Política de promoção da saúde parece tanto reforçar uma tendência prescritiva e normalizadora da saúde como produzir o debate acerca dos determinantes sociais e a adoção de 
uma concepção ampliada de saúde. Nesse sentido, politizar o debate é o primeiro passo na construção de uma política de promoção da saúde no Brasil. De um lado, reconhecer o protagonismo dos sujeitos na construção da saúde tem se mostrado uma importante ferramenta na divulgação de um conceito

\section{Referências}

ALMEIDA FILHO, N. Bases históricas da epidemiologia. Cadernos de Saúde Pública, Rio de Janeiro, v. 2, n. 3, p. 304-311, 1986.

AROUCA, A. S. S. O dilema preventivista: contribuição para a compreensão e crítica da medicina preventiva. 197 f. 1975. Tese (Doutorado em Ciências Médicas) - Campinas: Faculdade de Ciências Médicas, Universidade Estadual de Campinas, 1975.

BAPTISTA, T. W. F. Políticas de saúde no pós-constituinte: um estudo da política implementada a partir da produção normativa dos Poderes Executivo e Legislativo no Brasil. 2003. 346 p. Tese (Doutorado em Saúde Pública) - Universidade do Estado do Rio de Janeiro, Rio de Janeiro, 2003.

BAPTISTA, T. W. F.; MATTOS, R. A. Sobre política (ou o que achamos pertinente refletir para analisar políticas). In: (Org.). Caminhos para análise das políticas de saúde. Rio de Janeiro, 2011. Mimeo.

BARATA, R. B. Epidemiologia social. Revista brasileira de epidemiologia, São Paulo, v. 8, n. 1, p. 7-17, 2005.

BRASIL. Ministério da Saúde. Política Nacional de Promoção da Saúde. Brasília, DF: Ministério da Saúde, 2002a.

Ministério da Saúde. Portaria $n^{\circ}$ 399, de 22 de fevereiro de 2006. Divulga o Pacto pela Saúde 2006 - Consolidação do SUS e aprova as Diretrizes Operacionais do Referido Pacto. Brasília, DF, 2006. Disponível em: <http://bvsms.saude.gov.br/bvs/ ampliado de saúde, mas, de outro, é preciso reforçar a responsabilidade do Estado na produção de condições de vida condizentes com as necessidades da população, para não se correr o risco de se afirmar uma política que, principalmente, culpabiliza e responsabiliza o indivíduo pela sua não saúde.

saudelegis/gm/2006/prt0399_22_02_2006.html>. Acesso em: 23 out. 2015

Ministério da Saúde. Portaria No 2.446/GM de 11 de Novembro de 2014. Redefine a Política Nacional de Promoção da Saúde (PNPS). Brasília, DF, 2014.

Ministério da Saúde. Secretaria de Políticas de Saúde. Relatório de Gestão 2000-2002. Brasília, DF: Ministério da Saúde, 2002b.

BUSS, P. M.; CARVALHO, A. I. Desenvolvimento da promoção da saúde no Brasil nos últimos vinte anos (1988-2008). Ciência \&t Saúde Coletiva. Rio de Janeiro, v. 14, n. 6, p. 2305-2316, 2009.

BUSS, P. M.; PELLEGRINI FILHO, A. A saúde e seus determinantes sociais. Physis, Rio de Janeiro, v. 17, n. 1, p. $77-93,2007$.

CAMPOS, G. W. S.; BARROS, R. B.; CASTRO, A. M. Avaliação de política nacional de promoção da saúde. Ciência \&t Saúde Coletiva, Rio de Janeiro, v. 9, n. 3, p. 745-749, 2004.

FAGNANI, E. Política Social no Brasil (1964-2002): entre a cidadania e a caridade. 2005. $605 \mathrm{f}$. Tese (Doutorado em Ciências Econômicas) - Universidade Estadual de Campinas, Campinas, 2005.

FERREIRA, M. S.; CASTIEL, L. D.; CARDOSO, M. H. C. A. Atividade física na perspectiva da Nova Promoção da Saúde: contradições de um programa institucional. Ciência \&t Saúde Coletiva, Rio de Janeiro, v. 16, n. 1, p. $865-872,2011$. 
FERREIRA, M. S.; CASTIEL, L. D. Which empowerment, which Health Promotion? Conceptual convergences and divergences in preventive health practices. Cadernos de Saúde Pública, Rio de Janeiro, v. 25, n. 1, p. 68-76, 2009

ROCHA, D. G. et al. Processo de revisão da Política Nacional de Promoção da Saúde: múltiplos movimentos simultâneos. Ciência \& Saúde Coletiva, Rio de Janeiro, v. 19, n. 11, p. 4313-4322, 2014.

ROSEN, G. Da polícia médica à medicina social: ensaios sobre a história da assistência médica. Rio de Janeiro: Graal, 1980.

ROUQUAYROL, M. Z.; ALMEIDA FILHO, N.

Epidemiologia \&t Saúde. 5. ed. Rio de Janeiro: MEDSI, 1999.
SILVA, P. F. A.; BAPTISTA, T. W. F. Os sentidos e disputas na construção da Política Nacional de Promoção da Saúde. Physis, Rio de Janeiro, v. 24, n. 2, p. 441-465, 2014.

TERRIS, M.; CARVALHO, D. M. As relações dinâmicas da epidemiologia com a sociedade: a conferência Robert Cruikshank. Cadernos de Saúde Coletiva, Rio de Janeiro, v. 13, n. 2, p. 545-566, 2005.

Recebido para publicação em maio de 2015

Versão final em agosto de 2015

Confllito de interesses: inexistente

Suporte financeiro: não houve 